\title{
Evaluation of the Antioxidative Properties of $N$-Acylamino-Substituted Tricyclic Imides
}

\author{
Melek Gul, ${ }^{1}$ Irem Kulu, ${ }^{2}$ Aysegul Peksel, ${ }^{2}$ and Nuket Ocal ${ }^{2}$ \\ ${ }^{1}$ Faculty of Science and Arts, University of Amasya, 05100 Amasya, Turkey \\ ${ }^{2}$ Faculty of Science and Arts, Yildiz Technical University, Davutpasa Campus, Esenler, 34220 Istanbul, Turkey \\ Correspondence should be addressed to Irem Kulu; iremkulu@gmail.com
}

Received 25 April 2013; Revised 26 July 2013; Accepted 26 July 2013

Academic Editor: Esteban P. Urriolabeitia

Copyright (c) 2013 Melek Gul et al. This is an open access article distributed under the Creative Commons Attribution License, which permits unrestricted use, distribution, and reproduction in any medium, provided the original work is properly cited.

New $\mathrm{N}$-acylamino-substituted tricyclic imides have been screened for scavenging ability against the free radical 2,2-diphenyl-1picryl-hydrazyl (DPPH*), chelating activity on ferrous ions, and reductive potential. The results were compared with synthetic antioxidants BHT, BHA, and Trolox. The compounds exhibited different levels of antioxidant activity in all tests.

\section{Introduction}

$N$-substituted imides, such as maleimides [1], isohematinic acids [2], and especially bicyclic and tricyclic derivatives such as tandospirone derivatives $[3,4]$, were found to be remarkable due to variable pharmacological properties, and thus present antibiotic [5], fungicidal [6], analgesic [7], anxiolytic, and cytostatic effects [8]. The imide moiety is an integral structural part of various important bioactive molecules such as fumaramidmycin, granulatimide, isogranulatimide, and rebeccamycin. These molecules are reported to exhibit antidepressant, antitumor, anti-inflammatory, and antimicrobial activities $[9,10]$. On the other hand, various bicyclic structures such as epiboxidine and epibatidine are biologically important molecules (Figure 1). A literature search reveals that certain compounds with antitumor activity, and in particular molecules able to interact with DNA, are characterized by the presence of both an extended $\pi$-system and an imide function [11-13]. Apart from biological activities, imide derivatives are useful in the reactions involving condensation, alkylation, acylation, and cyclocondensation.

Oxidation is essential to many living organisms for the production of energy to fuel biological processes. However, oxygen-centered free radicals or other reactive oxygen species (ROS), which are continuously produced in vivo, result in cell death and tissue damage. The role of oxygen radicals has been implicated in several diseases, including cancer, diabetes, cardiovascular diseases, neural disorders, skin irritations, inflammations, and aging [14, 15]. Antioxidants deactivate and scavenge free radicals and inhibit the effect of oxidants by donating hydrogen atom or chelating metals. Synthetic antioxidants such as butylated hydroxyanisole (BHA) and butylated hydroxytoluene (BHT) are used as additives in foods to prevent oxidation of lipids. Besides, BHA and BHT are restricted by legislative rules because of doubts over their toxic and carcinogenic effects [16]. Therefore, there is a growing request and interest for safer antioxidants in food and pharmaceutical applications.

The Heck reaction, in particular, is widely used as an important method to build biologically active compounds in synthetic chemistry and the pharmaceutical industry [17, 18]. As an extension of the Heck reaction, Pd-catalyzed hydroarylation of alkynes and alkenes continues to attract researchers' interest in simple coupling processes and cyclization reactions $[19,20]$. In the presence of triphenylarsine as a ligand $[21,22]$ the palladium-catalyzed hydroarylation of the easily accessible, unsaturated tricyclic $N$-substituted imides such as aryl- and methyl-substituted, epibatidine, epiboxidine, and tandospirone analogs have been proven to be a stereoselective, versatile, and high-yield approach for the synthesis of the corresponding aryl and heteroaryl derivatives [23-31].

Recently, we synthesized $N$-acylamino-substituted tricyclic imides by the palladium-catalyzed hydroarylation 


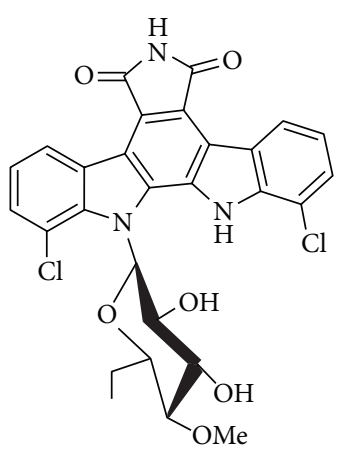

(a)

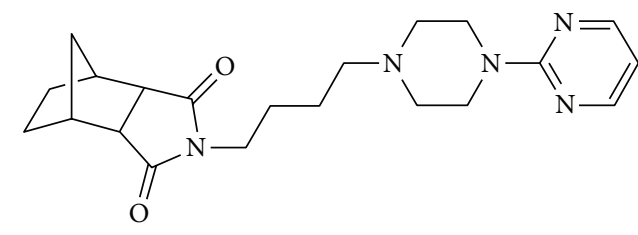

(b)

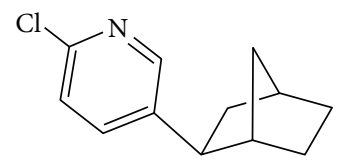

(c)

Figure 1: (a) Rebeccamycin, (b) tandospirone, and (c) epibatidine.

reactions and characterized by spectral methods [32]. Here, we focused on the effect of these Heck compounds on the antioxidant activity. Using different chemical reactionbased assays, new synthesized $N$-acylamino-substituted tricyclic imide molecules have been screened for scavenging ability against the free radical 2,2-diphenyl-1-picryl-hydrazyl $\left(\mathrm{DPPH}^{\circ}\right)$, chelating activity on ferrous ions, and reductive potential. The results were compared with the synthetic antioxidants BHT, BHA, and Trolox.

\section{Results and Discussion}

2.1. Chemistry. The synthesis of tricyclic imides were undertaken by Diels-Alder and acylation reactions by known procedures (Figure 2). Aryl- and heteroaryl-substituted $\mathrm{N}$ acylamino-substituted tricyclic imide derivatives were synthesized by the reductive Heck conditions (Figure 3).

We also selected 5-iodo-3-methylisoxazole and 2-chloro5 -iodopyridine as the arylation reagents because of the structural similarity with epibatidine and epiboxidine [33, $34]$ which are known to behave as a potent $\alpha 4 \beta 2$ nicotinic receptors. In this study, we analyzed the antioxidant effect of these reagents.

\subsection{Antioxidant Activity Studies}

2.2.1. Reducing Power. Fe(III) reduction is often used as an indicator of electron-donating activity, which is an important mechanism of antioxidant action, and can be strongly correlated with other antioxidant properties. In the reducing power assay, the presence of antioxidants results in the reduction of the $\mathrm{Fe}^{3+} /$ ferricyanide complex to its ferrous form. Figure 4 shows the extension of the reduction, in terms of absorbance values at $700 \mathrm{~nm}$, for the samples ranging in concentration from 25 to $100 \mu \mathrm{g} / \mathrm{mL}$. From a comparison of the absorbance at $700 \mathrm{~nm}$, the reducing power of the synthesized compounds was not concentration dependent. Compounds $\mathbf{4 a - b}, \mathbf{4 d}, \mathbf{5 b}-\mathbf{c}$, and $\mathbf{6 a}-\mathbf{f}$ showed the best reducing activity when compared with other tested compounds. These activities were found significantly similar for all samples. This may be due to the fact that these molecules meet hydrophilicity, stereochemical, and electronic requirements of the target in a better way as compared to other molecules. On the other hand, compounds $\mathbf{6 a}-\mathbf{f}$, which possess an $\mathrm{Ar}^{1}$ group introduced in position $\mathrm{C} 5$ of the heterocyclic ring, were more active than those in which such an Ar group is not attached in position $\mathrm{C} 5$, suggesting that conjugated double bonds and electronegative atoms in the ring system are involved in the reducing power activity. Compounds $\mathbf{6 c}$ and 6f that contain epibatidine and epiboxidine structure units, respectively, are known as biologically important groups and are expected to exhibit higher activity. This was confirmed by our results. The presence of alkene - $\mathrm{O}_{-},-\mathrm{S}_{-},-\mathrm{N}-$, and $-\mathrm{Cl}-$ on the heterocyclic ring system seems to increase the activity of compounds. Compounds $\mathbf{1}, \mathbf{3}$, and $\mathbf{4 c}$ showed the moderate activity. Compounds 2, 5a, and $\mathbf{5 d}$ and all concentrations showed weaker activity than the other compounds and the standards. Standard antioxidants BHA, BHT and Trolox were approximately 2 -fold more active than the samples.

2.2.2. Metal Chelating Activity. The ferrous ion $\left(\mathrm{Fe}^{2+}\right)$ chelating effect of the newly synthesized compounds is presented in Figure 5. Compounds 4a, 5a, and 6a-f showed moderate chelating activity on ferrous ions at an incubation time of $30 \mathrm{~min}$. Other compounds tested gave an excellent chelating ability at the same conditions. The results were compared with EDTA at the same concentrations. None of the extracts appeared to be better chelators of iron(II) ions than the positive control EDTA in this assay system. At $100 \mu \mathrm{g} / \mathrm{mL}$ concentration, EDTA was given $96 \%$ chelating effect on ferrous ions at an incubation time of $30 \mathrm{~min}$.

2.2.3. Free Radical Scavenging Activity. The free radical scavenging action is known as an important mechanism of antioxidation. 1,1-diphenyl-2-picryl-hydrazyl ( $\left.\mathrm{DPPH}^{*}\right)$ is used as a free radical to evaluate the antioxidative activity of some synthetic sources. The disappearance of $\mathrm{DPPH}^{*}$ is directly proportional to the amount of antioxidants present in the reaction mixture. Antioxidants react with stable free radical 1,1-diphenyl-2-picryl-hydrazyl and convert it to a 1,1-diphenyl-2-picryl-hydrazine. The transfers of hydrogen or electron from antioxidant to $\mathrm{DPPH}^{*}$ occur at different redox potentials and also depend on the structure of the antioxidant. Among all the samples, compounds 1, 2, 3, 4b, 
<smiles>Cc1cc(C(=O)NN2C(=O)C3C4C=CC(O4)C3C2=O)on1</smiles>

Figure 2: Synthesis of tricyclic imides, 1, 2, and 3.<smiles>O=CNN1C(=O)C2C3CC([Al])C(C3)C2C1=O</smiles>

(a)<smiles>CC(=O)c1ccco1</smiles><smiles>Cc1cc(C(=O)NN2C(=O)C3C4CC([Al])C(O4)C3C2=O)on1</smiles><smiles>COc1ccc(C(C)(C)C)cc1</smiles>

(b)

(1)

FIGURE 3: Synthesis of $N$-acylamino-substituted tricylic imides.

4c, 5a, 6a, and 6d showed the highest free radical scavenging activity at the concentration $25-100 \mu \mathrm{g} / \mathrm{mL}$. The results for all the compounds are shown in Figure 6. The free radical scavenging effect was not concentration dependent. However, it was generally observed that the effect increased as the concentration of the compounds $\mathbf{6 c - f}$ increased to a certain extent. Scavenging activity of BHA, BHT, and Trolox as known antioxidants was higher than that of samples. From these results, it can be stated that the samples tested have the moderate ability to scavenge free radicals and could serve as free radical inhibitors or scavengers according to the synthetic antioxidants.

The radical scavenging activities of the new compounds, expressed as an $\mathrm{IC}_{50}$ value, ranged from 6.46 to $81.63 \mu \mathrm{g} / \mathrm{mL}$. $\mathrm{IC}_{50}$ values (the inhibitory concentration at which the DPPH radicals were scavenged by $50 \%$ ) of compounds $\mathbf{6 b}, \mathbf{6 c}, \mathbf{6 e}$, and $6 f$ were higher than that of other compounds, which were comparable. A higher DPPH radical scavenging activity is associated with a lower $\mathrm{IC}_{50}$ value. It was evident that the compounds $\mathbf{6 b}, \mathbf{6 c}, \mathbf{6 e}$, and $\mathbf{6 f}$ did show the radical scavenging ability to act as antioxidants (Table 1).

\section{Conclusion}

In summary, free radical scavenging, metal chelating, and reducing power activities of tested synthesized compounds were screened. Our results showed that the compounds have a mild antioxidant activity at various antioxidant systems in vitro. The newly compounds were potent radical scavengers, and their antioxidant capacities seem to be related to their

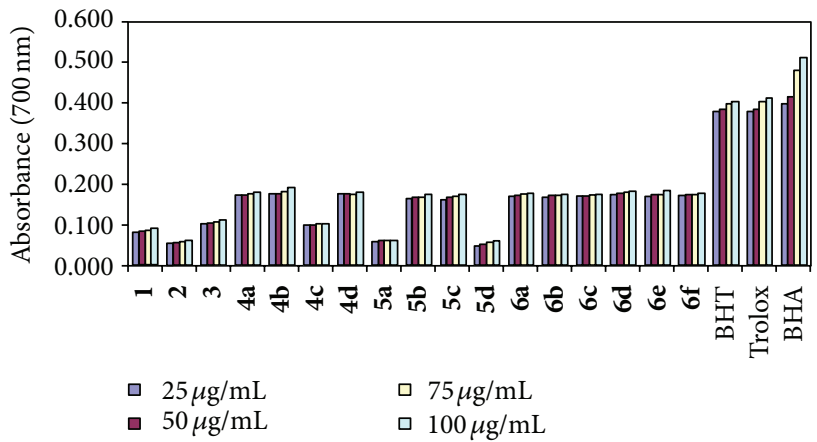

FIGURE 4: Reducing power activity of new compounds.

chemical compositions. Compounds $\mathbf{6 c}$ and $\mathbf{6 f}$ exhibited the highest radical scavenging activity than other compounds tested at $100 \mu \mathrm{g} / \mathrm{mL}$ concentration. These compounds contain epibatidine and epiboxidine structure part, respectively. The further studies suggested the pharmacological and biological importance of the epibatidine and epiboxidine groups. Our results confirm their effect. $\mathrm{Ar}^{1}$ substitutions at the $\mathrm{C} 5$ position are an attractive site for reductive potential. In addition, the benzyl-substituted compound $\mathbf{4 a}$ also gave the highest chelating activity.

\section{Experimental Section}

4.1. Chemicals. The antioxidant activities of the $N$ acylamino-substituted tricyclic imides were evaluated 


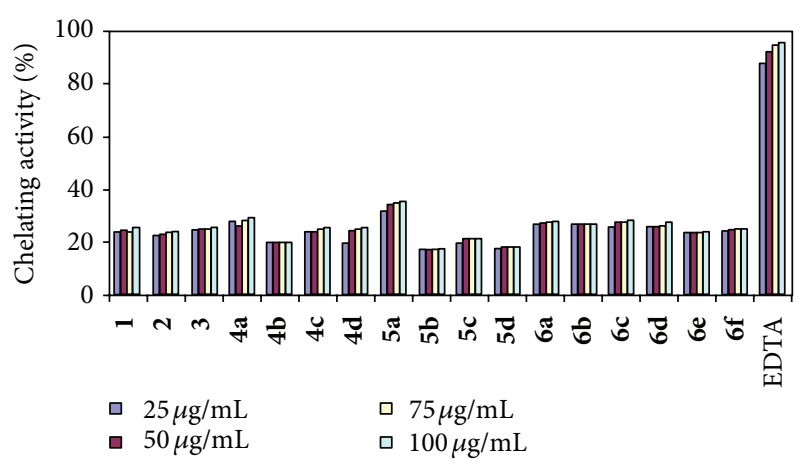

FIGURE 5: Metal chelating activity of new compounds.

based on the ability of the compounds to scavenge DPPH radicals, to reduce $\mathrm{Fe}(\mathrm{III})$ to $\mathrm{Fe}(\mathrm{II})$, and to bind to $\mathrm{Fe}(\mathrm{II})$ ions. The standard chemicals, 6-hydroxy-2,5,7,8-tetramethylchroman-2-carboxylic acid (Trolox), the stable free radical 1,1-diphenyl-2-picryl-hydrazyl (DPPH ${ }^{\circ}$ ), and trichloroacetic acid (TCA) were obtained from Sigma (Sigma-Aldrich $\mathrm{GmbH}$, Germany). Butylated hydroxyanisole (BHA) and butylated hydroxytoluene (BHT) were provided from Fluka (Buchs, Switzerland). Unless specified otherwise, all other reagents and solvents used were of analytical grade obtained from commercial suppliers.

\subsection{Antioxidant Activity Studies}

4.2.1. Reducing Power. In the reducing power assay, the presence of reductants (antioxidants) in the samples results in the reduction of the $\mathrm{Fe}^{3+} /$ ferricyanide complex to its ferrous form. The reducing powers of the samples BHA, BHT, and Trolox were determined according to the method described by Oyaizu [35]. Various concentrations of the samples $(25-100 \mu \mathrm{g})$ in $1 \mathrm{~mL}$ of distilled water were mixed with $2.5 \mathrm{~mL}$ of phosphate buffer $(0.2 \mathrm{M}, \mathrm{pH} 6.6)$ and $2.5 \mathrm{~mL}$ potassium ferricyanide $\left[\mathrm{K}_{3} \mathrm{Fe}(\mathrm{CN})_{6}\right](1 \%$, w/v), and the mixture was incubated at $50^{\circ} \mathrm{C}$ for $30 \mathrm{~min}$. Afterwards, $2.5 \mathrm{~mL}$ of trichloroacetic acid $(10 \%, \mathrm{w} / \mathrm{v})$ was added to the mixture and centrifuged at $3000 \mathrm{rpm}$ for $10 \mathrm{~min}$. Finally, $2.5 \mathrm{~mL}$ of upperlayer solution was mixed with $2.5 \mathrm{~mL}$ distilled water and $0.5 \mathrm{~mL} \mathrm{FeCl}_{3}(0.1 \%, \mathrm{w} / \mathrm{v})$, and the absorbance was measured at $700 \mathrm{~nm}$. Trolox, BHA, and BHT were used as standard antioxidants.

4.2.2. Metal Chelating Activity. The chelating activity of the new $\mathrm{N}$-acylamino-substituted tricyclic imide compounds on ferrous ions $\left(\mathrm{Fe}^{2+}\right)$ was measured according to the method of Decker and Welch [36]. Aliquots of $1 \mathrm{~mL}$ of different concentrations $(25,50,75$ and $100 \mu \mathrm{g} / \mathrm{mL})$ of the samples were mixed with $3.7 \mathrm{~mL}$ of deionized water. The mixture was incubated with $\mathrm{FeCl}_{2}(2 \mathrm{mM}, 0.1 \mathrm{~mL})$ for $30 \mathrm{~min}$. After incubation, the reaction was initiated by addition of ferrozine $(5 \mathrm{mM}$ and $0.2 \mathrm{~mL}$ ) for $10 \mathrm{~min}$ at room temperature, and then the absorbance was measured at $562 \mathrm{~nm}$ in a spectrophotometer. A lower absorbance indicates a higher chelating power. The chelating activity of the extract on $\mathrm{Fe}^{2+}$ was compared with

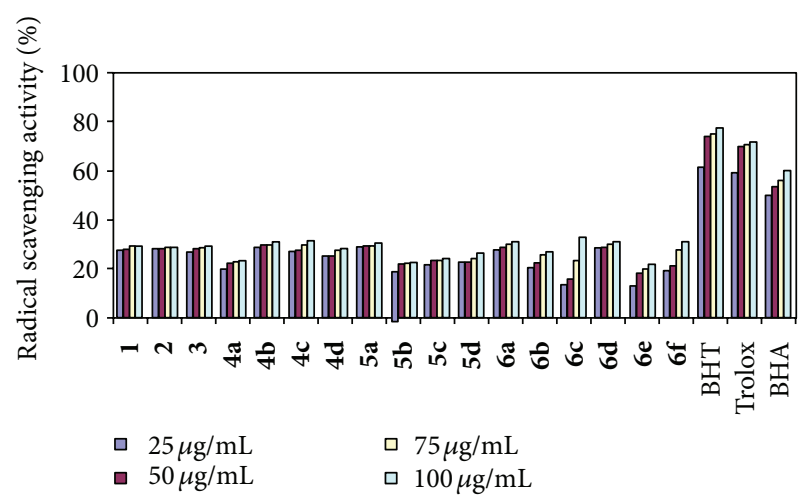

FIGURE 6: Radical scavenging activity (\%) of different concentration of new compounds.

TABLE 1: Radical scavenging activity $\left(\mathrm{IC}_{50}: \mu \mathrm{g} / \mathrm{mL}\right)$ of new compounds.

\begin{tabular}{lc}
\hline Compounds & $\begin{array}{c}\text { Free radical scavenging activity } \\
\mathrm{IC}_{50}(\mu \mathrm{g} / \mathrm{mL})\end{array}$ \\
\hline $\mathbf{1}$ & 35.53 \\
$\mathbf{2}$ & 81.63 \\
$\mathbf{3}$ & 28.13 \\
$\mathbf{4 a}$ & 25.78 \\
$\mathbf{4 b}$ & 27.16 \\
$\mathbf{4 c}$ & 16.95 \\
$\mathbf{4 d}$ & 21.80 \\
$\mathbf{5 a}$ & 36.77 \\
$\mathbf{5 b}$ & 39.14 \\
$\mathbf{5 c}$ & 35.58 \\
$\mathbf{5 d}$ & 21.48 \\
$\mathbf{6 a}$ & 19.08 \\
$\mathbf{6 b}$ & 14.24 \\
$\mathbf{6 c}$ & 6.79 \\
$\mathbf{6 d}$ & 22.47 \\
$\mathbf{6 e}$ & 14.10 \\
$\mathbf{6 f}$ & 6.46 \\
BHT & 0.90 \\
Trolox & 1.85 \\
BHA & 1.72 \\
\hline
\end{tabular}

that of EDTA at the same concentrations. Chelating activity was calculated using the following formula: metal chelating activity $(\%)=[1-$ (absorbance of sample/absorbance of control) $] \times 100$. Control test was performed without addition of the sample.

4.2.3. Free Radical Scavenging Activity. The free radical scavenging activity of the new $\mathrm{N}$-acylamino-substituted tricyclic imide compounds were measured with 1,1-diphenyl-2-picrylhydrazyl $\left(\mathrm{DPPH}^{\circ}\right)$ using the slightly modified methods of Brand-Williams et al. Briefly [37], $20 \mathrm{mg} / \mathrm{L} \mathrm{DPPH}^{\bullet}$ solution in methanol was prepared, and $1.5 \mathrm{~mL}$ of this solution was added to $0.75 \mathrm{~mL}$ of the sample, butylated hydroxyanisole 
(BHA), butylated hydroxytoluene (BHT), and Trolox (25$100 \mu \mathrm{g} / \mathrm{mL}$ ). The mixture was shaken vigorously, and the decrease in absorbance at $517 \mathrm{~nm}$ was measured at $30 \mathrm{~min}$. Water $(0.75 \mathrm{~mL})$ in place of the sample was used as control. The percent inhibition activity was calculated using the following equation:free radical scavenging effect $(\%)=\left[\left(A_{0}-\right.\right.$ $\left.\left.A_{1}\right) / A_{0}\right] \times 100$, where $A_{0}$ is the absorbance of the control reaction and $A_{1}$ is the absorbance in the presence of the sample solution. The sample concentration providing $50 \%$ inhibition $\left(\mathrm{IC}_{50}\right)$ was calculated from the graph of inhibition percentage plotted against sample concentration.

\section{References}

[1] F. Zentz, A. Valla, R. Le Guillou, R. Labia, A. Mathot, and D. Sirot, "Synthesis and antimicrobial activities of N-substituted imides," Il Farmaco, vol. 57, no. 5, pp. 421-426, 2002.

[2] R. M. DiPardo, M. A. Patane, R. C. Newton et al., "Cyclic imides as potent and selective $\alpha$-1A adrenergic receptor antagonists," Bioorganic and Medicinal Chemistry Letters, vol. 11, no. 14, pp. 1959-1962, 2001.

[3] J. Kossakowski and M. Jarocka, "Synthesis of new N-substituted cyclic imides with an expected anxiolytic activity. XVII. Derivatives of 1-ethoxybicyclo[2.2.2]-oct-5-one-2,3-dicarboximide," Il Farmaco, vol. 56, no. 10, pp. 785-789, 2001.

[4] J. Kossakowski, A. Bielenica, B. Mirosław, A. E. Kozioł, I. Dybała, and M. Struga, "4-Azatricyclo[5.2.2.02,6] undecane3,5,8-triones as potential pharmacological agents," Molecules, vol. 13, no. 8, pp. 1570-1583, 2008.

[5] V. C. Filho, T. Pinheiro, R. J. Nunes, R. A. Yunes, A. B. Cruz, and E. Moretto, "Antibacterial activity of $N$-phenylmaleimides, $N$ phenylsuccinimides and related compounds. Structure-activity relationships," Farmaco, vol. 49, no. 10, pp. 675-677, 1994.

[6] Z. Shen, Y. Fan, F. Li, X. Chen, and Y. Shen, "Synthesis of Nsubstituted dimethylmaleimides and their antifungal activities against Sclerotinia sclerotiorum," Journal of Pest Science, vol. 86, no. 2, pp. 353-360, 2013.

[7] F. Mahle, T. R. Guimarães, A. V. Meira et al., "Synthesis and biological evaluation of $\mathrm{N}$-antipyrine-4-substituted amino-3chloromaleimide derivatives," European Journal of Medicinal Chemistry, vol. 45, no. 11, pp. 4761-4768, 2010.

[8] F. Wang, H. Yin, C. Yue, S. Cheng, and M. Hong, "Synthesis, structural characterization, in vitro cytotoxicities and DNAbinding properties of triphenylantimony $\operatorname{di}(N$-oxy phthalimide) and di(N-oxy succinimide) complexes," Journal of Organometallic Chemistry, vol. 738, pp. 35-40, 2013.

[9] M. F. Braña, A. Gradillas, A. Gómez et al., "Synthesis, biological activity, and quantitative structure-activity relationship study of azanaphthalimide and arylnaphthalimide derivatives," Journal of Medicinal Chemistry, vol. 47, no. 9, pp. 2236-2242, 2004.

[10] S. M. Sondhi, R. Rani, A. D. Diwvedi, and P. Roy, "Synthesis of some heterocyclic imides and azomethine derivatives under solvent free condition and their anti-inflammatory activity evaluation," Journal of Heterocyclic Chemistry, vol. 46, no. 6, pp. 1369-1374, 2009.

[11] F. Anizon, L. Belin, P. Moreau et al., "Syntheses and biological activities (topoisomerase inhibition and antitumor and antimicrobial properties) of rebeccamycin analogues bearing modified sugar moieties and substituted on the imide nitrogen with a methyl group," Journal of Medicinal Chemistry, vol. 40, no. 21, pp. 3456-3465, 1997.
[12] W. G. Walter, "Antitumor imide derivatives of 7oxabicyclo[2.2.1] heptane-2,3-dimethyl-2,3-dicarboxylic acid," Journal of Pharmaceutical Sciences, vol. 78, no. 1, pp. 66-67, 1989.

[13] S. M. Sondhi, R. Rani, P. Roy, S. K. Agrawal, and A. K. Saxena, "Microwave-assisted synthesis of N-substituted cyclic imides and their evaluation for anticancer and anti-inflammatory activities," Bioorganic and Medicinal Chemistry Letters, vol. 19, no. 5, pp. 1534-1538, 2009.

[14] B. Halliwell and J. M. C. Gutteridge, Free Radicals in Biology and Medicine, Clarendon Press, New York, NY, USA, 1989.

[15] T. Finkel and N. J. Holbrook, "Oxidants, oxidative stress and the biology of ageing," Nature, vol. 408, no. 6809, pp. 239-247, 2000.

[16] L. Sun, J. Zhang, X. Lu, L. Zhang, and Y. Zhang, "Evaluation to the antioxidant activity of total flavonoids extract from persimmon (Diospyros kaki L.) leaves," Food and Chemical Toxicology, vol. 49, no. 10, pp. 2689-2696, 2011.

[17] D. Mitchell and H. Yu, "Synthetic applications of palladiumcatalyzed hydroarylation and related systems," Current Opinion in Drug Discovery and Development, vol. 6, no. 6, pp. 876-883, 2003.

[18] Z. L. Wei, C. George, and A. P. Kozikowski, "Synthesis of 5endo-, 5-exo-, 6-endo- and 6-exo-hydroxylated analogues of epibatidine," Tetrahedron Letters, vol. 44, no. 19, pp. 3847-3850, 2003.

[19] E. Negishi and A. de Meijere, Eds., Handbook of Organopalladium Chemistry for Organic Synthesis, John Wiley \& Sons, New York, NY, USA, 2002.

[20] I. P. Beletskaya and A. V. Cheprakov, "Heck reaction as a sharpening stone of palladium catalysis," Chemical Reviews, vol. 100, no. 8, pp. 3009-3066, 2000.

[21] J. C. Namyslo, J. Storsberg, J. Klinge et al., "The hydroarylation reaction-scope and limitations," Molecules, vol. 15, no. 5, pp. 3402-3410, 2010.

[22] A. Otten, J. C. Namyslo, M. Stoermer, and D. E. Kaufmann, “2(het)aryl-substituted 7-azabicyclo[2.2.1] heptane systems," European Journal of Organic Chemistry, no. 9, pp. 1997-2001, 1998.

[23] C. Yolacan, E. Bagdatli, N. Ocal, and D. E. Kaufmann, "Epibatidine alkaloid chemistry: 5. Domino-heck reactions of azabicyclic and tricyclic systems," Molecules, vol. 11, no. 8, pp. 603$614,2006$.

[24] E. Bagdatli, N. Ocal, and D. E. Kaufmann, "An investigation into domino-Heck reactions of $\mathrm{N}$-acylamino-substituted tricyclic imides: synthesis of new prospective pharmaceuticals," Helvetica Chimica Acta, vol. 90, no. 12, pp. 2380-2385, 2007.

[25] G. Goksu, M. Gul, N. Ocal, and D. E. Kaufmann, "Hydroarylation of bicyclic, unsaturated dicarboximides: access to arylsubstituted, bridged perhydroisoindoles," Tetrahedron Letters, vol. 49, no. 17, pp. 2685-2688, 2008.

[26] G. Goksu, N. Ocal, and D. E. Kaufmann, "Reductive heck reactions of $\mathrm{N}$-methyl-substituted tricyclic imides," Molecules, vol. 15, no. 3, pp. 1302-1308, 2010.

[27] M. Gul, I. Kulu, O. T. Gunkara, and N. Ocal, "Reductive Heck reactions and $[3+2]$ cycloadditions of unsaturated $\mathrm{N}, \mathrm{N}^{\prime}$ bistricyclic imides," Acta Chimica Slovenica, vol. 60, pp. 87-94, 2013.

[28] C. Celik, I. Kulu, N. Ocal, and D. E. Kaufmann, "DominoHeck reactions of carba- and oxabicyclic, unsaturated dicarboximides: synthesis of aryl-substituted, bridged perhydroisoindole derivatives," Helvetica Chimica Acta, vol. 92, no. 6, pp. 1092-1101, 2009. 
[29] I. Kulu and N. Ocal, "The synthesis of epiboxidine and related analogues as potential pharmacological agents," Helvetica Chimica Acta, vol. 94, no. 11, pp. 2054-2060, 2011.

[30] I. Kulu, G. Goksu, B. O. Sucu, A. Kopruceli, N. Ocal, and D. E. Kaufmann, "Synthesis of new aryl-substituted tandospirone and epiboxidine analogues and isoxazoline derivatives," Organic Preparations and Procedures International, vol. 45, no. 1, pp. 4456, 2013.

[31] O. T. Gunkara, B. O. Sucu, N. Ocal, and D. E. Kaufmann, "Synthesis of new aryl(hetaryl)-substituted tandospirone analogues under reductive Heck type hydroarylations with expected anxiolytic activity," Chemical Papers, vol. 67, no. 6, pp. 643-649, 2013.

[32] M. Gul, I. Kulu, and N. Ocal, "Hydroarylation reactions of $\mathrm{N}$-acylaminosubstituted tricyclic imides," Journal of Chemical Research, vol. 6, pp. 345-350, 2013.

[33] B. Badio, H. M. Garraffo, C. V. Plummer, W. L. Padgett, and J. W. Daly, "Synthesis and nicotinic activity of epiboxidine: an isoxazole analogue of epibatidine," European Journal of Pharmacology, vol. 321, no. 2, pp. 189-194, 1997.

[34] L. Rizzi, C. Dallanoce, C. Matera et al., "Epiboxidine and novel-related analogues: a convenient synthetic approach and estimation of their affinity at neuronal nicotinic acetylcholine receptor subtypes," Bioorganic and Medicinal Chemistry Letters, vol. 18, no. 16, pp. 4651-4654, 2008.

[35] M. Oyaizu, "Studies on product of browning reaction prepared from glucose amine," Japanese Journal of Nutrition, vol. 44, no. 6, pp. 307-315, 1986.

[36] E. A. Decker and B. Welch, "Role of ferritin as a lipid oxidation catalyst in muscle food," Journal of Agricultural and Food Chemistry, vol. 38, no. 3, pp. 674-677, 1990.

[37] W. Brand-Williams, M. E. Cuvelier, and C. Berset, "Use of a free radical method to evaluate antioxidant activity," LWT-Food Science and Technology, vol. 28, no. 1, pp. 25-30, 1995. 

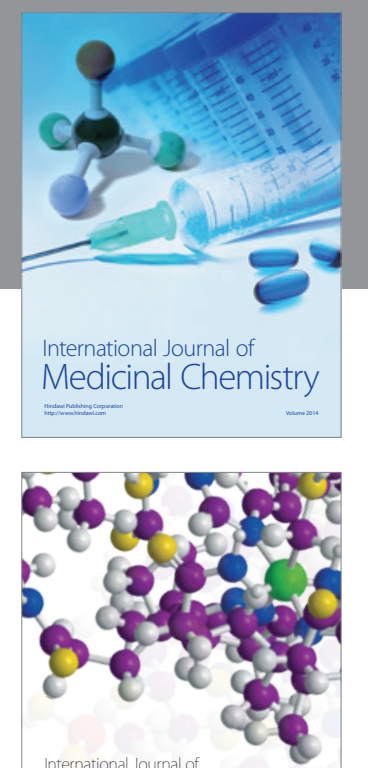

\section{Carbohydrate} Chemistry

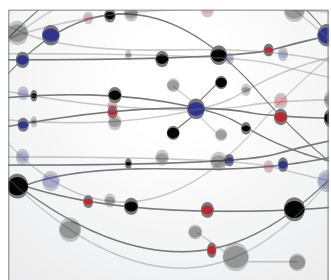

The Scientific World Journal
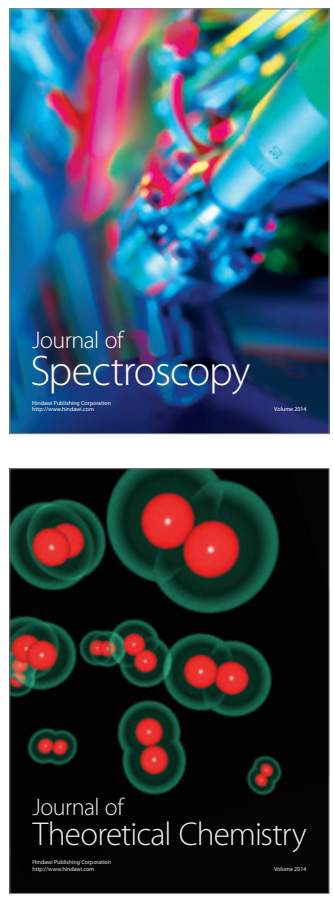
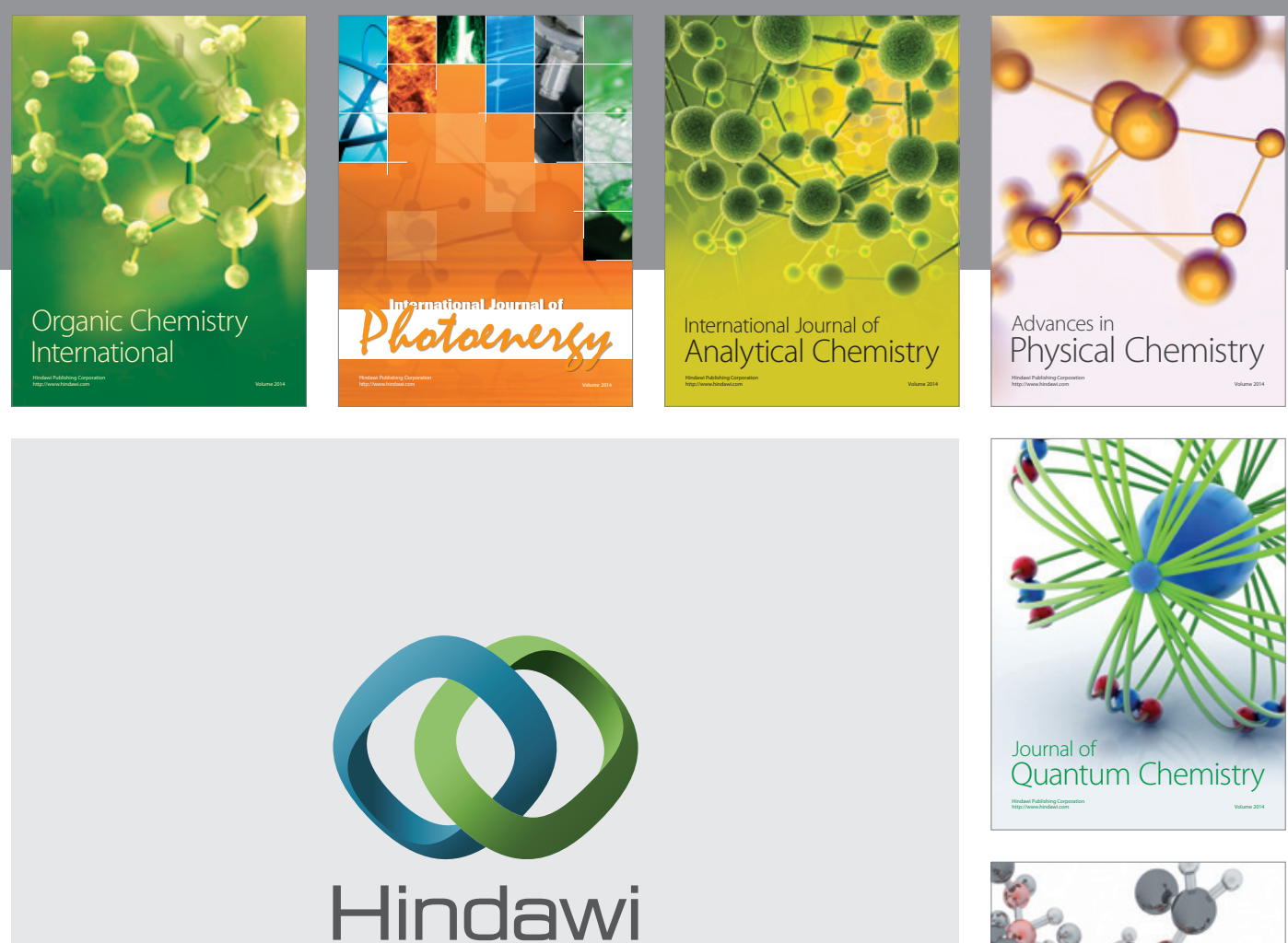

Submit your manuscripts at

http://www.hindawi.com

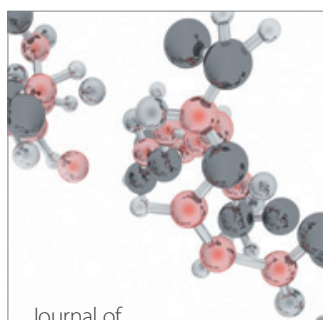

Analytical Methods

in Chemistry

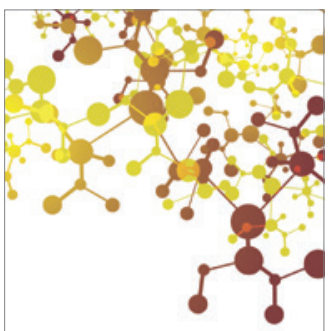

Journal of

Applied Chemistry

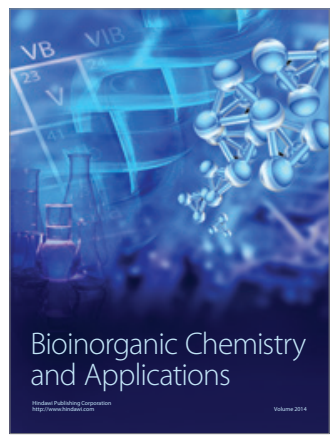

Inorganic Chemistry
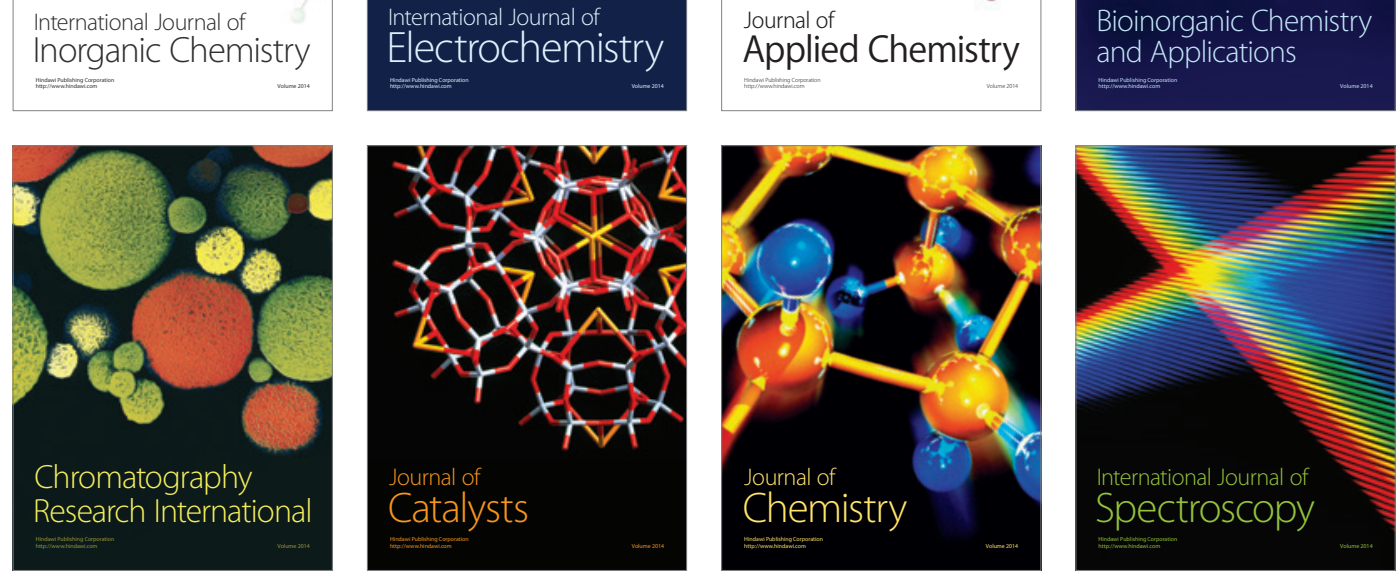